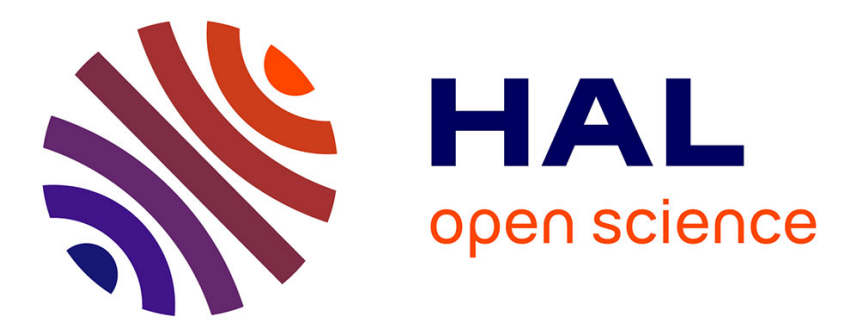

\title{
Nitromethane pyrolysis in shock tubes and a micro flow reactor with a controlled temperature profile
}

\author{
Olivier Mathieu, Nabiha Chaumeix, Yoshimichi Yamamoto, Said Abid, \\ Claude-Etienne Paillard, Takuya Tezuka, Hisashi Nakamura, Clayton \\ Mulvihill, Eric Petersen
}

\section{To cite this version:}

Olivier Mathieu, Nabiha Chaumeix, Yoshimichi Yamamoto, Said Abid, Claude-Etienne Paillard, et al.. Nitromethane pyrolysis in shock tubes and a micro flow reactor with a controlled temperature profile. Proceedings of the Combustion Institute, 2021, 10.1016/j.proci.2020.07.132 • hal-03098687

\section{HAL Id: hal-03098687 https://hal.science/hal-03098687}

Submitted on 5 Jan 2021

HAL is a multi-disciplinary open access archive for the deposit and dissemination of scientific research documents, whether they are published or not. The documents may come from teaching and research institutions in France or abroad, or from public or private research centers.
L'archive ouverte pluridisciplinaire HAL, est destinée au dépôt et à la diffusion de documents scientifiques de niveau recherche, publiés ou non, émanant des établissements d'enseignement et de recherche français ou étrangers, des laboratoires publics ou privés. 


\section{Nitromethane Pyrolysis in Shock Tubes and a Micro Flow Reactor With a Controlled Temperature Profile}

Olivier Mathieu ${ }^{1 *}$ Nabiha Chaumeix ${ }^{2}$, Yoshimichi Yamamoto ${ }^{3}$, Said Abid², Claude-Etienne Paillard², Takuya Tezuka $^{3}$, Hisashi Nakamura ${ }^{3}$, Clayton Mulvihill ${ }^{1}$, Eric L. Petersen ${ }^{1}$

'J. Mike Walker '66 Department of Mechanical Engineering, Texas A\&M University, College Station, TX, USA

2Institut de Combustion, Aérothermique, Réactivité et Environnement, CNRS Orléans, Orléans, France

3Institute of Fluid Science, Tohoku University, Sendai, Japan

Abstract: Nitromethane has many applications, such as in racing, as a gasoline fuel additive, and as a monopropellant. Despite a large number of studies and the small size of the molecule, the combustion chemistry of nitromethane is still not well understood. To improve models, the pyrolysis of nitromethane $\left(\mathrm{CH}_{3} \mathrm{NO}_{2}\right)$ was investigated experimentally in shock tubes and in a micro flow reactor with a controlled temperature profile (MFR), under dilute conditions. Several spectroscopic diagnostics were used in the shock tubes to follow the concentration time histories of $\mathrm{CO}, \mathrm{H}_{2} \mathrm{O}$ (both using IR laser absorption), and $\mathrm{CH}_{3} \mathrm{NO}_{2}$ (UV light absorption). A quadrupole mass spectrometer was used to measure $\mathrm{CH}_{3} \mathrm{NO}_{2}, \mathrm{NO}_{2}, \mathrm{CH}_{4}, \mathrm{C}_{2} \mathrm{H}_{4}$, and

$\mathrm{C}_{2} \mathrm{H}_{2}$ at various temperatures with the MFR. These unique experimental results were compared to modern, detailed kinetics models from the literature, and no mechanism was able to reproduce these data over the wide range of conditions investigated. Predictions for the $\mathrm{CO}$ and $\mathrm{H}_{2} \mathrm{O}$ levels were generally inaccurate, and the $\mathrm{CH}_{4}$, $\mathrm{C}_{2} \mathrm{H}_{4}$, and $\mathrm{C}_{2} \mathrm{H}_{2}$ predictions were poor in most cases for the MFR data. Importantly, all models largely differ in their predictions. A numerical analysis was performed to identify ways to improve the next generation of nitromethane models. Results indicate that nitromethane decomposition needs to be improved below $1050 \mathrm{~K}$, and that hydrocarbon-NOx interactions still need to be further investigated.

Keywords: Nitromethane, pyrolysis, shock tubes, micro-flow reactor

Corresponding author:

*Olivier Mathieu

Email: olivier.mathieu@,tamu.edu

Preprint submitted to Proceedings of the Combustion Institute 


\section{Introduction}

Nitromethane $\left(\mathrm{CH}_{3} \mathrm{NO}_{2}, \mathrm{NM}\right)$ can be used in several applications such as a racing fuel [1], a fuel additive for automotive applications [2,3], a reference fuel to understand the combustion of monopropellant [4,5] or a monopropellant itself [6]. Moreover, NM-filled cartridges can be used to generate a controlled deflagration to rapidly restore routes blocked by collapsed structures and rescue victims after earthquakes [7].

These applications, along with the fundamental interest in understanding the combustion chemistry of nitro compounds [8] (which can also help understanding better hydrocarbon/NOx interactions), explain why nitromethane combustion is receiving a lot of interest. One can mention studies in shock tubes [9-16], flames $[1,17-20]$, and plug flow and jet-stirred reactors $[8,21,22]$. Despite a large body of data for an apparently simple molecule, recent studies in flames or shock tubes showed that the combustion chemistry of nitromethane is still not well understood $[12,17,20]$.

One good example can be found in the rapid thermal dissociation of $\mathrm{CH}_{3} \mathrm{NO}_{2}$, which is one of the key features of its combustion $[8,9,13,14,20,23-26]$. Despite the importance of this dissociation, recent studies treat this step differently: Brequigny et al. [1] and Glarborg et al. [27] used only one decomposition reaction: $\mathrm{CH}_{3} \mathrm{NO}_{2}(+\mathrm{M}) \leftrightarrows \mathrm{CH}_{3}+\mathrm{NO}_{2}(+\mathrm{M})$ (R1) with the reaction rate from Glarborg et al. [28]. Mathieu et al. [9] used the reactions proposed by Annesley et al. [13] where the roaming isomerization of nitromethane was considered (resulting in two decomposition reactions: $\mathrm{CH}_{3} \mathrm{NO}_{2} \leftrightarrows \mathrm{CH}_{3}+\mathrm{NO}_{2}$ (R1) and $\mathrm{CH}_{3} \mathrm{NO}_{2} \leftrightarrows \mathrm{CH}_{3} \mathrm{O}+\mathrm{NO}$ (R2)) whereas Weng et al. [22] revisited R1, used R2 from [13], and introduced another pathway: $\mathrm{CH}_{3} \mathrm{NO}_{2} \leftrightarrows \mathrm{HCNO}+\mathrm{H}_{2} \mathrm{O}(\mathrm{R} 3)$. Note that for the range of temperatures investigated herein, at $1 \mathrm{~atm}$, the rate constant of the $\mathrm{C}-\mathrm{N}$ bond cleavage $\mathrm{R} 1$ is higher than that of roaming isomerization (R2) and much larger than R3, which then can be ignored [22]. Finally, the most recent study of Shrestha et al. [8] considers only R1 and R2, but with reaction rates coming from Glarborg et al. [28] and Matsugi and Shiina [14], respectively.

More fundamental studies are required to improve NM models and, in the authors' opinion, it is now necessary to go beyond global kinetics data such as ignition delay times and laminar flame speeds. Accurate time histories and speciation of key species at various conditions are needed to further constrain the models, and a study of NM under pyrolysis conditions would also be beneficial to simplify the chemistry. The aim of 
this study was to provide such fundamental data, assess modern detailed kinetics mechanisms, and identify ways to improve $\mathrm{NM}$ chemistry. To do so, pyrolytic mixtures of $\mathrm{NM}$ were investigated. $\mathrm{CO}$ and $\mathrm{H}_{2} \mathrm{O}$ time histories were measured using laser absorption in shock tubes at Texas A\&M University (TAMU); NM time histories were obtained by UV-light absorption at ICARE-CNRS Orléans; and various species were characterized by a quadrupole mass spectrometer (QMS) in a micro-flow reactor with a controlled temperature profile (MFR) at Tohoku University. First are presented the experimental conditions investigated and the experimental setups used. The results are then presented and compared with modern detailed kinetics mechanisms from the literature (Brequigny et al. [1], Shrestha et al. [8], Weng et al. [21], Glarborg et al. [27], and Mathieu et al. [29]). Finally, a model analysis was performed, and recommendations were made to improve models.

\section{Experimental setups}

The conditions investigated in the present work are summarized in Table 1, and wide ranges of temperatures, pressures, and NM concentration were covered. Note that the $1.5 \% \mathrm{NM}$ condition was investigated with all apparatuses, between 1 and $2.2 \mathrm{~atm}$.

Table 1: Summary of the experimental conditions investigated during this study.

\begin{tabular}{|c|c|c|c|c|}
\hline Reactor & Diagnostic & Mixture composition & Temp. (K) & Pressure (atm) \\
\hline \multirow{2}{*}{$\begin{array}{c}\text { Shock } \\
\text { Tube } \\
\text { (TAMU) }\end{array}$} & $\mathrm{CO}-$ laser absorption & $0.005 \mathrm{CH}_{3} \mathrm{NO}_{2} / 0.2 \mathrm{He} / 0.795 \mathrm{Ar}$ & $900-1380$ & $1.55 \pm 0.25$ \\
\cline { 3 - 5 } & $\mathrm{H}_{2} \mathrm{O}-$ laser absorption & $0.015 \mathrm{CH}_{3} \mathrm{NO}_{2} / 0.2 \mathrm{He} / 0.785 \mathrm{Ar}$ & $900-1140$ & $2.2 \pm 0.15$ \\
\cline { 3 - 5 } & $0.005 \mathrm{CH}_{3} \mathrm{NO}_{2} / 0.995 \mathrm{Ar}$ & $940-1250$ & $1.05 \pm 0.15$ \\
\hline \multirow{2}{*}{$\begin{array}{c}\text { Shock } \\
\text { Tube } \\
\text { (ICARE) }\end{array}$} & $\begin{array}{c}\mathrm{CH}_{3} \mathrm{NO}_{2}-\mathrm{UV} \text { light } \\
\text { absorption }\end{array}$ & $0.015 \mathrm{CH}_{3} \mathrm{NO}_{2} / 0.985 \mathrm{Ar}$ & $1040-1240$ & $2.25 \pm 0.25$ \\
\cline { 2 - 5 } $\begin{array}{c}\text { MFR } \\
\text { (Tohoku) }\end{array}$ & $\begin{array}{c}\mathrm{CH}_{3} \mathrm{NO}_{2}, \mathrm{CH}_{4}, \mathrm{C}_{2} \mathrm{H}_{4}, \\
\mathrm{C}_{2} \mathrm{H}_{2}, \mathrm{NO}-\mathrm{QMS}\end{array}$ & $0.002 \mathrm{CH}_{3} \mathrm{NO}_{2} / 0.998 \mathrm{Ar}$ & $1040-1220$ & $3.84-8.62$ \\
\cline { 3 - 5 } $\mathrm{CH}_{3} \mathrm{NO}_{2} / 0.997 \mathrm{Ar}$ & $1060-1250$ & $1.76-8.28$ \\
\hline
\end{tabular}

Note that the $\mathrm{CO}$ formation was also measured for Helium-free mixtures. The addition of He was deemed necessary for vibrational relaxation, as detailed in Mathieu et al. [29]. However, another study from our group [30] did not show any appreciable benefits to adding He. In the present case, mixtures with and without He 
presented similar time histories in terms of both timing and $\mathrm{CO}$ level. The data for the NM/He/ $\mathrm{Ar}$ mixtures are presented here, but all the data for the NM/Ar mixtures are provided as Supplemental Material. Finally, the effect of impurities in the shock-tube results below was investigated using the work of Urzay and coworkers [31], showing that the impurities have virtually no effect on the profiles.

\subsection{Laser absorption shock tubes}

Laser diagnostics were employed in two different shock tubes at TAMU. These two facilities are relatively similar in that they are single-diaphragm, made of stainless steel, with a 7.62-cm i.d. driver section. Both have a larger driven section (15.24-cm i.d., 4.72-m long for the $\mathrm{CO}$ diagnostic; 16.2-cm i.d., 6.78-m long for $\mathrm{H}_{2} \mathrm{O}$ ) equipped with PCB P113A piezoelectric pressure transducers with a well-known spacing between them to measure the incident-wave velocities (determined at the endwall location with a curve-fit of the velocities measured between transducers). Post-reflected shock conditions were obtained with this extrapolated wave speed, in conjunction with the one-dimensional shock relations and the initial conditions in the test region. The uncertainty in the temperature determined behind reflected shock waves is within about $10-15 \mathrm{~K}$ and the timeaccuracy of all the shock tubes used herein is considered to be about $1 \mu$ s. The attenuation of monochromatic, $\mathrm{cw}$ laser light was used to determine the concentration of the target species using a Beer-Lambert relation: $I / I_{0}=\exp \left(-k v P_{\mathrm{abs}} L\right)$, where $I_{0}$ and $I$ are the transmitted and incident laser light intensities, $k v$ is the spectral absorption coefficient, $P_{\text {abs }}$ is the partial pressure of the absorbing species, and $L$ is the path length. The linestrengths from the HITRAN 2004 database [32] were used to calculate $k v$, and $I / I_{0}$ was measured.

\subsubsection{CO measurements}

A quantum cascade laser was used to generate the light at $4566.17 \mathrm{~nm}$ to access the fundamental $\mathrm{R}(12)$ transition of the $v^{\prime \prime}=0 \mathrm{CO}$ band. The laser was centered on the $\mathrm{R}(12)$ transition using a removable $\mathrm{CO} / \mathrm{Ar}$ absorption cell before each test. $I$ and $I_{0}$ were monitored using two InSb detectors fitted with a bandpass filter centered at $4500 \mathrm{~nm}$, with a full width of $500 \mathrm{~nm}$, allowing for the broadband emission levels entering the 
detectors to be $<0.3 \%$ of the absorption signal. For more details on the $\mathrm{CO}$ diagnostic and the uncertainties in the measurements ( $\pm 3.8 \%$ ), see Mathieu et al. [29] and references herein.

\subsection{2. $\mathrm{H}_{2} \mathrm{O}$ measurements}

Water formation was followed using the attenuation of light at $1388.140 \mathrm{~nm}$ coming from a Toptica Photonics tunable diode laser to access the $5_{5,1} \leftarrow 5_{5,0}$ transition at $1388.1389 \mathrm{~nm}$ within the $v 1+v 3$ fundamental band. The slight shift in wavelength is to account for the pressure shift of the line center. This diagnostic is described in more detail in Mathieu et al. [33], and the uncertainty on the water concentration is estimated to be below 6\% [30].

\subsection{UV Light absorption shock tube}

The stainless-steel shock tube used at ICARE-CNRS Orléans is a double-diaphragm type, with a 1-m diver section (114.2 $\mathrm{mm}$ i.d.) and 3.75-m driven section (52.5 $\mathrm{mm}$ i.d.). The driven section is equipped with 4 shock detectors (CHIMIE METAL A25L05B) to determine the incident-wave velocity at the endwall location and related post-shock conditions, as described above. Measurements were situated $12 \mathrm{~mm}$ from the endwall through $\mathrm{CaF}_{2}$ windows, with a light source (deuterium lamp HAMAMATSU C1518) and a monochromator (JOBIN-YVON HR250M, equipped with a HAMAMATSU R977photomultiplicator). The NM absorption spectrum was determined during the course of this study between 210.4 and $370.7 \mathrm{~nm}$ (spectrum available as supplemental material). Based on this spectrum, the absorption of NM was followed at $220 \mathrm{~nm}$ for most experiments, whereas some experiments performed in the highest pressure and temperature domains of the 1.5\% NM mixture necessitated higher wavelengths $(225-230 \mathrm{~nm})$, to avoid saturation of the signal. Like for the laser-absorption measurements, the absorption intensity is proportional to the concentration of the absorbing species following the Beer-Lambert law. The absorption coefficient of NM in Ar was determined at each

wavelength, for the entire range of temperatures investigated (visible in Sup. Mat.). Since the absorption of 
products from NM decomposition cannot be fully excluded at $220 \mathrm{~nm}$, only the first part of the profile (between 200 and $400 \mu$ s for the highest and lowest temperatures, respectively) was considered.

2.3 Micro-flow reactor with a controlled temperature profile

The MFR is composed of a 2-mm-i.d. quartz tube heated by a hydrogen/air flat-flame burner providing a temperature ramp along the inner surface of the reactor channel. The burner can be moved along the reactor to vary the sampling position relative to the temperature profile. The maximum wall temperature (corresponding to the temperature of the inner surface of the reactor) was set at $1300 \mathrm{~K}$ during this study, and the measured wall temperature profile is shown in the figure presenting the results below. The uncertainty is $<$ $0.3 \mathrm{~mm}$ for the axial distance, and the temperature difference between top and bottom walls inside the reactor is small (approx. $10 \mathrm{~K}$ ), unaffecting the 1-D modeling. The NM/Ar mixture was supplied to the reactor at atmospheric pressure with an inlet mean flow velocity of $3 \mathrm{~cm} / \mathrm{s}$. A quartz micro-probe $(0.1 \mathrm{~mm}$ i.d.; more details in [34]) was fused on the sidewall of the reactor channel, forming a T-shaped reactor. The micro-probe was used to sample the gases in the reactor channel, after which they are introduced into a QMS through a fused-silica capillary. The temperature of the sampling line was kept at $373 \mathrm{~K}$ to prevent water condensation. Chemical reactions in the sampling line were negligible thanks to the rapid pressure and temperature reductions of the sampled gas [34]. The following species were identified and quantified by QMS: $\mathrm{NM}, \mathrm{NO}, \mathrm{CH}_{4}, \mathrm{C}_{2} \mathrm{H}_{2}$, and $\mathrm{C}_{2} \mathrm{H}_{4}$. Electro-ionization was used at an energy of $16 \mathrm{eV}$ for $\mathrm{CH}_{4}$ and $\mathrm{NM}$, and $10 \mathrm{eV}$ for $\mathrm{C}_{2} \mathrm{H}_{2}$ and $\mathrm{C}_{2} \mathrm{H}_{4}$, whereas photo-ionization was used for $\mathrm{NO}(10.8 \mathrm{eV})$ to minimize the fragmentation effects.

\subsection{Modeling procedure}

ANSYS Chemkin-Pro v19.0 was used to simulate the experiments. For the shock-tube results, the modeling was done using the closed homogeneous reactor module with U, V assumptions. For the MFR, the PREMIX code was used, where the flow field in the reactor channel was modeled as a one-dimensional, steady-state 
reactive flow without a boundary layer. A heat convection term between the gas and the reactor wall was added to the gas-phase energy equation. The experimentally measured wall temperature profile was used during computations, and radical quenching was not considered. More details on the MFR and on the modeling procedure can be found in [35] and references therein. Note that radical quenching on the reactor surface is negligibly small in the MFR [36]. When missing, the transport data necessary to model the MFR results were assembled by using the AramcoMech 3.0 ( $\mathrm{H}_{2} / \mathrm{O}_{2} /$ Hydrocarbons) and the Glarborg models (NM and NOx).

3. Experimental results and models comparison

\subsection{CO Measurements}

The CO formation from a $0.5 \% \mathrm{NM}$ /diluents mixture, at around $1.5 \mathrm{~atm}$, is visible in Fig. 1 for (a) low, (b) intermediate, and (c) high temperatures. As can be seen, the CO formation starts very rapidly and reaches a plateau value at a rate that increases with temperature. Note that the test time is not long enough for the lowtemperature case to observe this plateau, and that the plateau value is different from the equilibrium value, not reached in the time frame considered. At low temperature, literature models are all notably under-reactive, with the Mathieu and Glarborg model being the closest to the data. At intermediate temperature, $1126 \mathrm{~K}$, large differences between models can be observed. The Weng model is notably under-reactive and largely underpredicts the formation of $\mathrm{CO}$ by about $30 \%$. To a lesser extent, a similar observation can be made with the Shrestha model $(12 \%)$. The rapid, initial, growth in the CO signal is well-captured by the other models, although they are still slightly under-reactive, notably the Brequigny model.

Noticeable differences are also observed between models on the amount of $\mathrm{CO}$ reached during the test time. The Brequigny model predicts closely the amount of $\mathrm{CO}$ formed, whereas the Mathieu and Glarborg models over-estimate this value (by about 18 and 25\%, respectively). For the high-temperature case, the Weng and Shrestha models are still under-predicting CO (10 and 25\%, respectively), whereas the other models accurately predict the rise of the timing and slope of the initial CO formation. The Brequigny model slightly under-predicts the amount of $\mathrm{CO}$ at the inflexion point, but rapidly predicts the experimental profile with high 
accuracy. Around the inflexion point, the models of Mathieu and, to a larger extent, Glarborg, over-predict the $\mathrm{CO}$ amount. These two models then eventually predict the same CO concentration after $1.2 \mathrm{~ms}$, and the predictions and experimental data seem to be converging beyond the test time. Similar observations were made for the mixture with $1.5 \% \mathrm{NM}$, as can be seen in Supplementary Material.

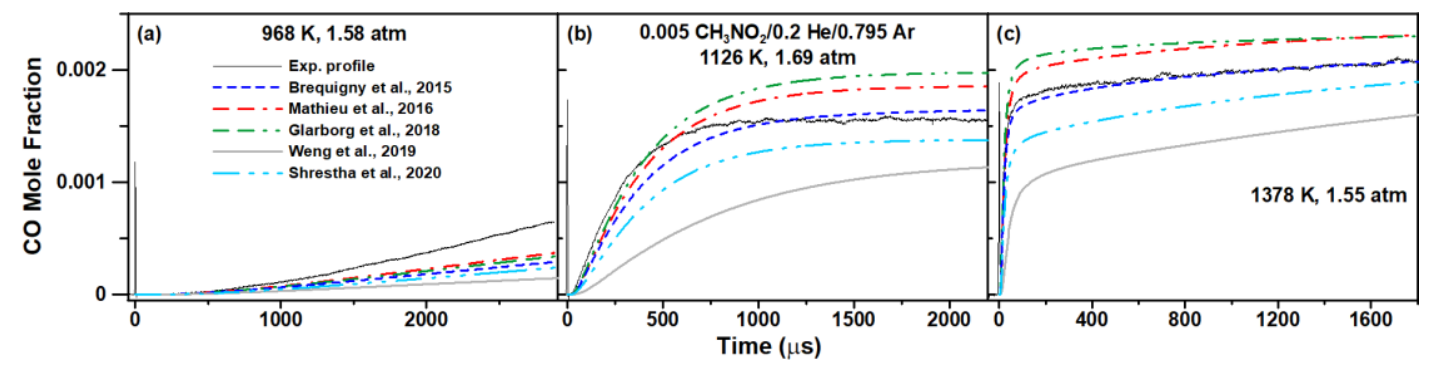

Figure 1: CO time histories and model comparisons for NM pyrolysis at (a) low, (b) intermediate, and (c) high temperature.

\section{2 $\mathrm{H}_{2} \mathrm{O}$ Measurements}

The formation of water around atmospheric pressure for a $0.5 \% \mathrm{NM} / \mathrm{Ar}$ mixture can be seen in Fig. 2. Like for $\mathrm{CO}$, the formation of $\mathrm{H}_{2} \mathrm{O}$ is too slow in the time frame studied to reach its equilibrium for the lowest temperatures. At this condition, all models are under-reactive, with the Mathieu model being slightly better than the other ones. Concerning the Weng model, results always show an under-reactivity and a lesser formation of water, at all conditions (a 15\% difference being observed at the plateau level of the high-temperature case (c)). As the temperature increases, the reactivity becomes similar for the three other models. The predicted level of $\mathrm{H}_{2} \mathrm{O}$ is also rapidly exceeding the experimental observations, and an observation of the complete set of data shows that it occurs for temperatures above around $1075 \mathrm{~K}$ for the Glarborg and Brequigny models, and for temperatures above $1164 \mathrm{~K}$ for the Mathieu and Shrestha models. At high temperatures, Fig. 2c, the Mathieu and Shrestha models both over-estimate the amount of water by around $12-15 \%$, whereas the Glarborg and Brequigny models over-estimate the water formation by around $20 \%$. Like for CO, similar observations were made for the mixture with 1.5\% NM (Supp. Mat.), although the amount of water predicted by the Brequigny 
model is now visibly higher than for the Glarborg model for this higher NM concentration, with the Shrestha model being the most accurate in terms of $\mathrm{H}_{2} \mathrm{O}$ concentration.

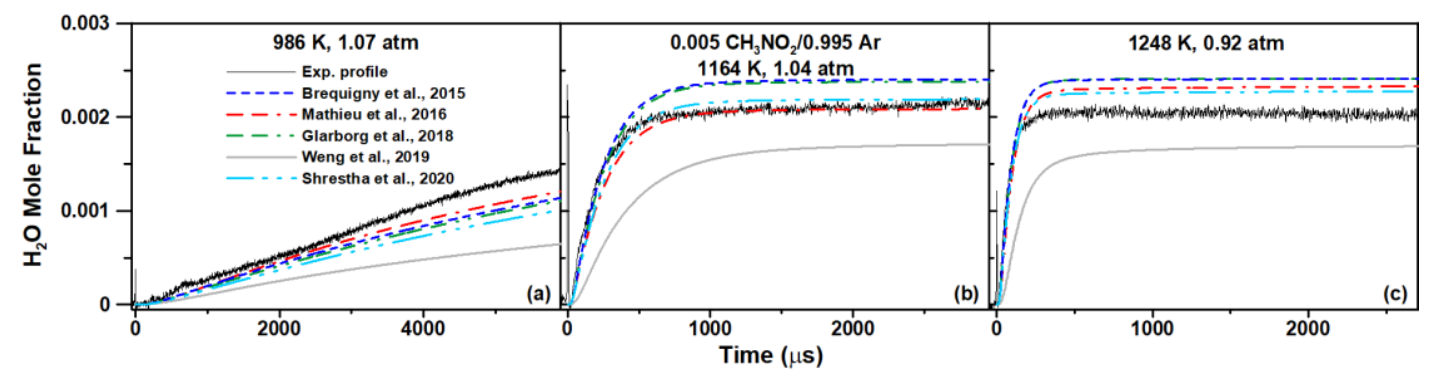

Figure 2: $\mathrm{H}_{2} \mathrm{O}$ time histories and model comparisons for NM pyrolysis at (a) low, (b) intermediate, and (c) high temperature.

\section{$3.3 \mathrm{CH}_{3} \mathrm{NO}_{2}$ Measurements}

Some representative profiles for NM decomposition are visible for the most-dilute case $(0.2 \% \mathrm{NM}$ in $\mathrm{Ar})$ at (a) low, (b) intermediate, and (c) high temperature in Fig. 3. As can be seen, less than $50 \%$ of the NM is decomposed within the time frame considered for the low-temperature case, whereas NM is fully decomposed by around $600 \mu$ s and $125 \mu$ s at intermediate and high temperatures, respectively. For these two last cases, predictions from all but Weng (under-reactive) models are accurate. However, while the Weng model is still under-reactive at low temperature, the four other mechanisms appear to be over-reactive. Similar results have been observed for the other conditions investigated, as visible in Supplementary Material.

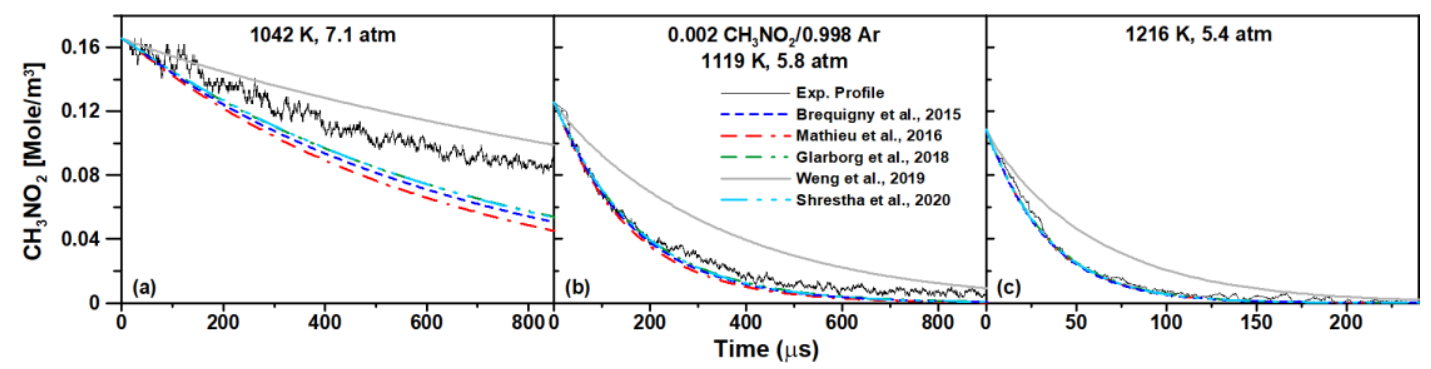


Figure 3: Comparison between experiments and models for $\mathrm{CH}_{3} \mathrm{NO}_{2}$ time histories during nitromethane pyrolysis at (a) low, (b) intermediate, and (c) high temperature.

\subsection{Micro Flow Reactor measurements}

The results for NM pyrolysis in a MFR are visible in Fig. 4. Concerning the NM profile (Fig. 4a), all models but, to a much lesser extent, the Brequigny et al. one predict a decomposition that is shifted towards lower temperatures $(750 \mathrm{~K} / x=5 \mathrm{~cm}$ instead of $950 \mathrm{~K} / x=5.4 \mathrm{~cm}$ for the experiments, the Brequigny et al. model being almost within the experimental uncertainties). Parallel to the NM consumption, a large amount of NO is formed, up to $12300 \mathrm{ppm}$ at around $1200 \mathrm{~K}(5.9 \mathrm{~cm})$ corresponding to more than $80 \%$ of the initial NM concentration. As the temperature reaches its maximum, $1300 \mathrm{~K}(6.4 \mathrm{~cm})$, about $1000 \mathrm{ppm}$ of NO is consumed. The Brequigny model predicts the timing of the NO formation accurately, but the amount of NO is too large (14355 ppm). Moreover, the small consumption of NO is not predicted. A similar NO level and lack of NO consumption are observed by the other mechanisms, with the NO formation starting too early. However, while the model of Mathieu et al. also predicts early NO formation, the maximum amount of NO is within the experimental uncertainty, and this model is the only one capturing the small NO consumption past $x=6 \mathrm{~cm}$ (although this consumption is not large enough next to the experiment).

At the same time NM is consumed and NO is formed, a relatively large amount of $\mathrm{CH}_{4}$ (up to $2360 \mathrm{ppm}$ ) is formed (Fig. $4 \mathrm{~b}$ ). As NO is consumed near $x=6.5 \mathrm{~cm}$, it is visible on the experimental profiles that the $\mathrm{CH}_{4}$ and $\mathrm{C}_{2} \mathrm{H}_{4}$ concentrations decrease in similar proportions, indicating that the two species are most likely interacting. Large differences in the predicted amount of $\mathrm{CH}_{4}$ can be observed between the models, with the Brequigny model presenting a methane profile that is accurately reproduced until after $x=6.5 \mathrm{~cm}$ (the model actually presenting an opposite trend, with an increase in the $\mathrm{CH}_{4}$ level). The Mathieu model also predicted the maximum amount of $\mathrm{CH}_{4}$ within the experimental uncertainty, but with a too-early formation and with a $\mathrm{CH}_{4}$ profile that increases, instead of the expected decrease, past $6 \mathrm{~cm}$. All the other models predict the $\mathrm{CH}_{4}$ 
formation too early, and in too large proportions, with the Glarborg model being the farthest (over-prediction by a factor of about 2).

Differences between the data and the models, and between the models, are larger for $\mathrm{C}_{2} \mathrm{H}_{4}$ (Fig. 4c), and $\mathrm{C}_{2} \mathrm{H}_{2}$ (Fig. $4 \mathrm{~d}$ ). For $\mathrm{C}_{2} \mathrm{H}_{4}$, a noticeable decrease in the maximum amount is also observed past $x=6.5 \mathrm{~cm}$, with most models predicting an opposite trend. This result and the opposite predictions for $\mathrm{CH}_{4}$ past $6.5 \mathrm{~cm}$ could indicate that the $\mathrm{CH}_{4} / \mathrm{C}_{2} \mathrm{H}_{4}$ and $\mathrm{NO}$ interactions need to be revisited in the models. All models predict the formation of ethylene starting too early, with the Glarborg et al. model being very close to the experimental data for the maximum $\mathrm{C}_{2} \mathrm{H}_{4}$ value registered. All other models over-predict the amount of ethylene, the farthest being the Brequigny model with an over-prediction by a factor larger than 5 . On the other hand, acetylene is under-predicted by all models but the Mathieu et al. one. The late formation of $\mathrm{C}_{2} \mathrm{H}_{2}$, past $x=6 \mathrm{~cm}$, is not captured by the models (where the $\mathrm{C}_{2} \mathrm{H}_{2}$ formation starts at $x=5.5 \mathrm{~cm}$ or before), and so is the decrease in the $\mathrm{C}_{2} \mathrm{H}_{2}$ signal past $x=7 \mathrm{~cm}$. The Brequigny model is within a factor 2 of the data, with the other models being worse, up to a factor of 11 for the mechanism from Glarborg and coworkers.

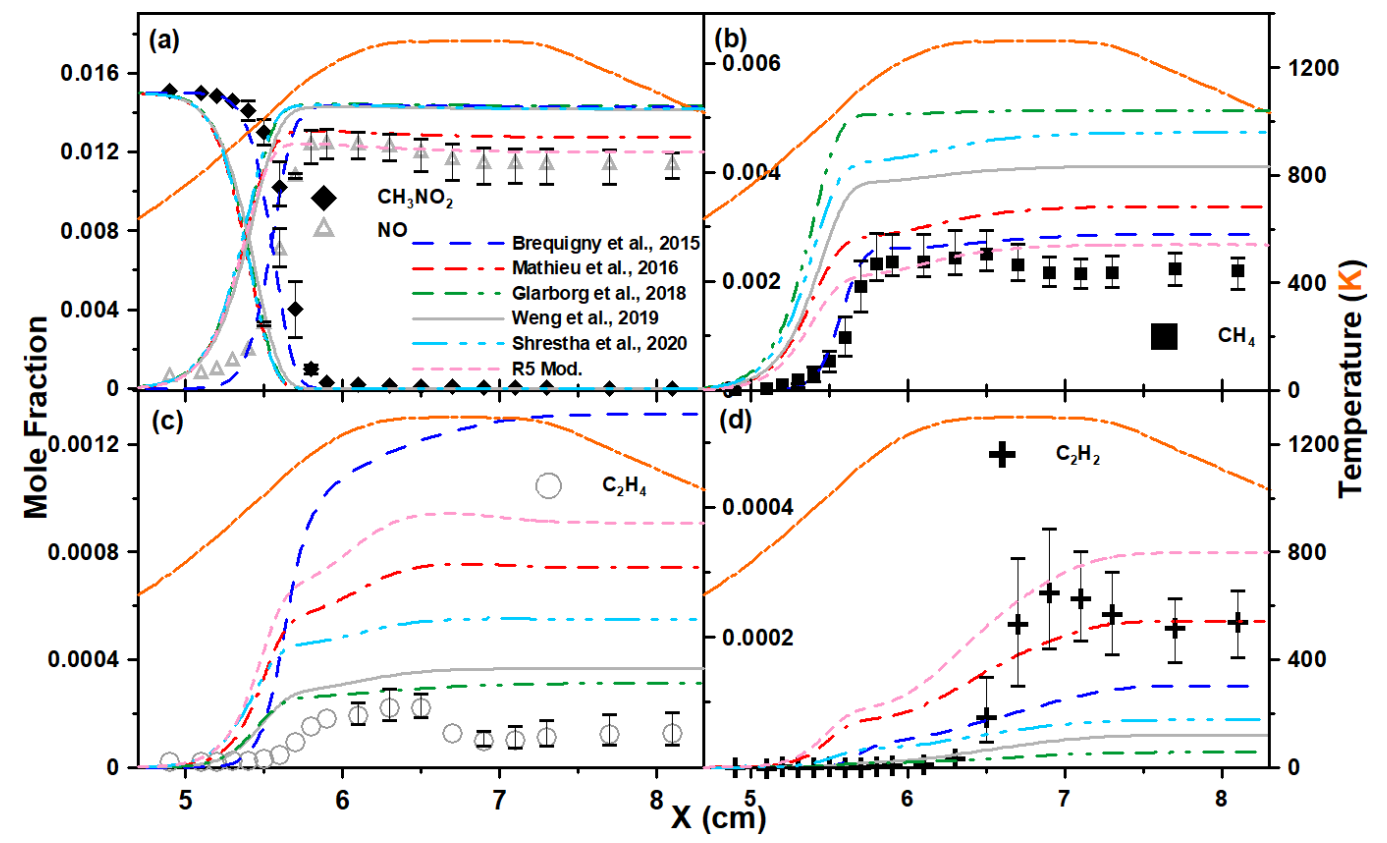

Figure 4: Comparison between experiment and models for (a) $\mathrm{CH}_{3} \mathrm{NO}_{2}$ and $\mathrm{NO}$; (b) $\mathrm{CH}_{4}$; (c) $\mathrm{C}_{2} \mathrm{H}_{4}$; and (d) $\mathrm{C}_{2} \mathrm{H}_{2}$ during the pyrolysis of nitromethane in a MFR. 


\section{Discussion}

The comparison between models and the data from this study demonstrated serious flaws in the pyrolysis chemistry of nitromethane. Notably, the decomposition of NM seems to be poorly predicted below $1050 \mathrm{~K}$ (MFR, shock tube), with most models being too reactive. On the other hand, issues at the NOx-hydrocarbon interaction level were revealed: (i) the same models appear to be under-reactive for predicting $\mathrm{CO}$ and $\mathrm{H}_{2} \mathrm{O}$ formation at these low temperatures; (ii) the predicted $\mathrm{CO}$ and $\mathrm{H}_{2} \mathrm{O}$ levels were wrong in most cases; and (iii) the predictions for $\mathrm{CH}_{4}, \mathrm{C}_{2} \mathrm{H}_{4}$, and $\mathrm{C}_{2} \mathrm{H}_{2}$ in $\mathrm{MFR}$ were poor. It can therefore be anticipated that the present data will be invaluable to help improving NM combustion chemistry and our current understanding of the interactions between NOx and hydrocarbons.

To understand the reasons behind these poor predictions, a numerical analysis was conducted using reaction pathway, sensitivity, and rate-of-production analyses for the models considered herein. Concerning the NM decomposition, R1 is by far the most important reaction for all models, followed by $\mathrm{R} 2$ for the models that include this pathway. The particularity of the Weng model (Fig. 3) is due to the fact that it uses a different rate for R1 than the ones typically utilized, and that it has an additional unique reaction, with a relatively high sensitivity: $\mathrm{CH}_{3} \mathrm{NO}_{2}+\mathrm{CH}_{3} \leftrightarrows \mathrm{CH}_{3} \mathrm{NO}+\mathrm{CH}_{3} \mathrm{O}$ (R4) (their new NM decomposition pathway, R3, being unimportant under our conditions).

The MFR results are of particular interest, as the concentration levels of many species were poorly predicted and as a second reactive phase observed experimentally at $x=6.5 \mathrm{~cm}$ was not captured by any model. Using the Mathieu et al. model (as it offers decent predictions for NO concentration and is not too far from the data for $\mathrm{CH}_{4}$ ), the numerical analysis shows the predominant role of the reaction $\mathrm{HNO}+\mathrm{CH}_{3} \leftrightarrows \mathrm{NO}+\mathrm{CH}_{4}(\mathrm{R} 5)$ in the formation of $\mathrm{CH}_{4}$ and NO. Dividing the reaction rate of $\mathrm{R} 5$ (from Rasmussen et al. [37]) by a factor 3 brings the $\mathrm{NO}$ and $\mathrm{CH}_{4}$ profiles in much better agreement with the data ("R5 mod." in Fig. 4), but also increases the $\mathrm{C}_{2} \mathrm{H}_{4}$ and $\mathrm{C}_{2} \mathrm{H}_{2}$ levels. While $\mathrm{C}_{2} \mathrm{H}_{2}$ remains in relative agreement with the data, $\mathrm{C}_{2} \mathrm{H}_{4}$ is now significantly over-estimated. This change in the rate of R5 does not impact the shock-tube results herein. To further illustrate 
the importance of this reaction, it is worth mentioning that using the reaction rate from Choi and Lin [38], used in the Glarborg and Shrestha models, largely increases the concentrations of $\mathrm{CH}_{4}$ and $\mathrm{NO}$, the latter being then identical to the prediction from the Glarborg model, the less accurate in this case (Fig. 4(c)). Note that reactions similar to R5 are not present in any model for molecules like $\mathrm{C}_{2} \mathrm{H}_{4}$ or $\mathrm{C}_{2} \mathrm{H}_{6}$, possibly leading to the poor predictions in the C2 species. Similarly, it is reasonable to think that the second reaction zone past $6.5 \mathrm{~cm}$ is not captured by the models due to missing interactions between hydrocarbon-type molecules and radicals with nitrogen-containing species.

Concerning the shock-tube results, the formation of $\mathrm{CO}$ will be used as an example to further illustrate the differences between models and to identify areas where the models need improvement. As seen in Fig. 1, a factor up to around 1.7 can be observed on the CO prediction at the plateau between the extremes, the Weng and Glarborg models. A rapid calculation shows that, when modeling the CO formation from a classical $\mathrm{CH}_{4} / \mathrm{O}_{2}$ mixture at $\phi=2$, the models considered herein rapidly converge toward the same level of CO in the time frame investigated (Supp. Mat.), indicating that the differences observed between the NM models in Fig. 1 are not due to the base hydrocarbon chemistry.

An equilibrium calculation on $\mathrm{CO}$ was also performed at the conditions of Fig. 1b, and all models predict similar values for CO equilibrium (3272-3279 ppm), except the Weng et al. model which predicted a slightly lower value at $3210 \mathrm{ppm}$. This difference, certainly due to the thermodynamic properties used, is not large enough to explain the discrepancy between the Weng model and the others in terms of CO predictions. Interestingly, all models show a similar main reaction pathway for $\mathrm{CO}$ formation under our conditions: R1 $\left(\mathrm{CH}_{3} \mathrm{NO}_{2} \leftrightarrows \mathrm{CH}_{3}+\mathrm{NO}_{2}\right)$ is always, by far, the main reaction behind NM consumption. R2 $\left(\mathrm{CH}_{3} \mathrm{NO}_{2} \leftrightarrows \mathrm{CH}_{3} \mathrm{O}+\mathrm{NO}\right)$, when present, or reactions between $\mathrm{CH}_{3} \mathrm{NO}_{2}$ and $\mathrm{H}$ or $\mathrm{OH}$ radicals to form $\mathrm{CH}_{2} \mathrm{NO}_{2}$ have a smaller contribution. In all models, the $\mathrm{CH}_{3}$ coming from $\mathrm{R} 1$ will then react either with another $\mathrm{CH}_{3}$ to form $\mathrm{C}_{2} \mathrm{H}_{6}$, or with $\mathrm{NO}_{2}$ (R6) to form $\mathrm{CH}_{3} \mathrm{O}$ and $\mathrm{NO}$ (like R2). Note that there are three different reaction rates used for $\mathrm{R} 6$, between the 5 models considered. The $\mathrm{CH}_{3} \mathrm{O}$ from $\mathrm{R} 6$ (and $\mathrm{R} 2$ ) will then rapidly produce $\mathrm{CO}$ via the following sequence: $\mathrm{CH}_{3} \mathrm{O} \rightarrow \mathrm{CH}_{2} \mathrm{O} \rightarrow \mathrm{HCO} \rightarrow \mathrm{CO}$. This sequence is the chief contributor 
to CO in our experiments, and it is essentially controlled by reactions from the base hydrocarbon chemistry, except the transition from $\mathrm{HCO}$ to $\mathrm{CO}$ which occurs mainly via $\mathrm{HCO}+\mathrm{M} \leftrightarrows \mathrm{H}+\mathrm{CO}+\mathrm{M}$ (R7) and $\mathrm{HCO}+\mathrm{NO} \leftrightarrows \mathrm{HNO}+\mathrm{CO}(\mathrm{R} 8)$

For all models, $\mathrm{R} 7$ is, by far, the main reaction producing $\mathrm{CO}$. In addition to having a similar main reaction pathway from $\mathrm{CH}_{3} \mathrm{O}$ to $\mathrm{CO}$, the rates of many of these reactions are similar between models. However, large discrepancies between the Glarborg and Weng models can be due to differences in the reaction rate selected for R7, and to two reactions contributing to $\mathrm{CO}$ formation present in the Glarborg model only: $\mathrm{CH}_{2} \mathrm{O}+\mathrm{H} \leftrightarrows \mathrm{H}+\mathrm{CO}+\mathrm{H}_{2}(\mathrm{R} 9)$ and $\mathrm{CH}_{2} \mathrm{O}+\mathrm{OH} \leftrightarrows \mathrm{H}+\mathrm{CO}+\mathrm{H}_{2} \mathrm{O}$ (R10). Note that $\mathrm{R} 10$ also produces $\mathrm{H}_{2} \mathrm{O}$, which contributes to the over-predictions of water.

Concerning the $\mathrm{C}_{2} \mathrm{H}_{6}$ pathway, models also suggest a similar main reaction path: $\mathrm{C}_{2} \mathrm{H}_{6} \rightarrow \mathrm{C}_{2} \mathrm{H}_{5} \rightarrow \mathrm{C}_{2} \mathrm{H}_{4} \rightarrow$ $\mathrm{C}_{2} \mathrm{H}_{3} \rightarrow \mathrm{C}_{2} \mathrm{H}_{2} \rightarrow \mathrm{CH}_{2} \mathrm{CO}$ after which $\mathrm{CH}_{3} \mathrm{CO}$ and $\mathrm{HCCO}$ are formed in various proportions between models, to eventually form CO. This path is less important for CO formation, but contains many NOx-hydrocarbon interactions. Judging by the level of predictions for $\mathrm{C}_{2} \mathrm{H}_{2}$ and $\mathrm{C}_{2} \mathrm{H}_{4}$ from the MFR results, as discussed earlier, these interactions are still not well understood and necessitate more work.

\section{Conclusions}

The pyrolysis of nitromethane was investigated experimentally in shock tubes by measuring $\mathrm{CO}, \mathrm{H}_{2} \mathrm{O}$ (IR laser absorption) and $\mathrm{CH}_{3} \mathrm{NO}_{2}$ (UV light absorption) time histories and in a MFR by measuring $\mathrm{CH}_{3} \mathrm{NO}_{2}, \mathrm{NO}$, $\mathrm{CH}_{4}, \mathrm{C}_{2} \mathrm{H}_{4}$, and $\mathrm{C}_{2} \mathrm{H}_{2}$ (QMS). Results were compared with the most recent detailed kinetics models from the literature, and it was found that no model is capable of predicting these data accurately over the entire range of conditions investigated. While the predictions for NM consumption in shock tubes and the MFR were generally too fast in most cases below $1050 \mathrm{~K}$, the $\mathrm{CO}$ and $\mathrm{H}_{2} \mathrm{O}$ formation were too slow at these temperatures. In additions, there is no trend among these recent models, some predicting too much $\mathrm{CO}$ and/or $\mathrm{H}_{2} \mathrm{O}$, whereas some consistently under-predict these values. A numerical analysis with the models showed that the interactions 
between hydrocarbons and NOx need to be revisited and that some reaction pathways are very likely to be missing. One can conclude that the data from the present study will be extremely useful to develop a more accurate detailed kinetics model for nitromethane combustion.

\section{Acknowledgments}

The work at Tohoku University was supported by the Collaborative Research Project of the Institute of Fluid Science, Tohoku University (J19I037) and the Research Association of Automotive Internal Combustion Engines (AICE-p190101). The work at TAMU was supported by the TEES Turbomachinery Laboratory and by the National Science Foundation, grant number CBET-1706825. Dr. Chaumeix would like to thank Vera Skjorli and Morten Seljeskog for performing part of the experiments.

\section{References}

[1] P. Brequigny, G. Dayma, F. Halter, C. Mounaïm-Rousselle, T. Dubois, P. Dagaut, Laminar burning velocities of premixed nitromethane/air flames: an experimental and kinetic modeling study, Proc. Combust. Inst. 35 (2015) $703-10$. [2] H. Ma, K. Kar, R. Stone, R. Raine, H. Thorwarth, Analysis of Combustion in a Small Homogeneous Charge Compression Assisted Ignition Engine, Int. J. Engine Res. 7 (2006) 237-253.

[3] R. F. Cracknell, J. C. G. Andrae, L. J. McAllister, M. Norton, H. L. Walmsley, The chemical origin of octane sensitivity in gasoline fuels containing nitroalkanes, Combust. Flame 156 (2009) 1046-1052.

[4] S. Kelzenberg, N. Eisenreich, W. Eckl, V. Weiser, Modelling nitromethane combustion propellants, Explos Pyrotech. 24 (1999) 189-194.

[5] E. Boyer, K. K. Kuo, Modeling of nitromethane flame structure and burning behavior, Proc. Combust. Inst. 31 (2007) 2045-2053.

[6] Kenneth W. McCown III, Eric L. Petersen, Effects of nano-scale additives on the linear burning rate of nitromethane, Comb. Flame 161 (2014) 1935-1943.

[7] K. Uenishi, H. Yamachi, K. Yamagami, R. Sakamoto, Dynamic fragmentation of concrete using electric discharge impulses, Constr. Build. Mater. 67B (2014) 170-179.

[8] K. P. Shrestha, N. Vin, O. Herbinet, L. Seidel, F. Battin-Leclerc, T. Zeuch, F. Mauss, Insights into nitromethane combustion from detailed kinetic modeling - Pyrolysis experiments in jet-stirred and flow reactors, Fuel 261 (2020) 116349.

[9] J. N. Bradl, Shock-wave decomposition of nitroparaffins part 1.-mass-spectrometric study of nitromethane decomposition, Trans. Faraday Soc. 57 (1961) 1750-1756.

[10] N. M. Kuznetsov, Yu. P. Petrov, S. V. Turetskii, Kinetics of $\mathrm{NO}_{2}$ Formation upon the Decomposition of Nitromethane behind Shock Waves and the Possibility of Nitromethane Isomerization in the Course of the Reaction. Kinetics and Catalysis 53 (2012) 1-12.

[11] O.Mathieu, B. Giri, A. R. Agard, T. N. Adams, J. D. Mertens, E. L.Petersen, Nitromethane ignition behind reflected shock waves: Experimental and numerical study, Fuel 182 (2016) 597-612. 
[12] Y. Shang, J. Shi, H. Ning, R. Zhang, S.-N. Luo, Significance of reaction $\mathrm{CH}_{3}+\mathrm{NO}=\mathrm{H}_{2} \mathrm{CN}+\mathrm{OH}$ in two-stage ignition of nitromethane, Fuel 256 (2019) 115956.

[13] C. J. Annesley, J. B. Randazzo, S. J. Klippenstein, L. B. Harding, A. W. Jasper, Y. Georgievskii, B. Ruscic, R. S. Tranter. Thermal dissociation and roaming isomerization of nitromethane: experiment and theory. J Phys Chem A 119 (2015) 7872-7893.

[14] A. Matsugi, H. Shiina, Thermal decomposition of nitromethane and reaction between $\mathrm{CH}_{3}$ and $\mathrm{NO}_{2}, \mathrm{~J}$ Phys $\mathrm{Chem}$ A 121 (2017) 4218-4224.

[15] J. D. Nauclér, Y. Li, E. J. K. Nilsson, H. J. Curran, A. A. Konnov, An experimental and modeling study of nitromethane $+\mathrm{O}_{2}+\mathrm{N}_{2}$ ignition in a shock tube, Fuel 186 (2016) 629-638.

[16] Z. Gao, M. Yang, C. Tang, F. Yang, K. Yang, F.Deng, Z. Huang, Measurements of the High Temperature Ignition Delay Times and Kinetic Modeling Study on Oxidation of Nitromethane, Comb. Sci. Technol. 192 (2020), 313-334.

[17] Z. Tian, L. Zhang, Y. Li, T. Yuan, F. Qi, An experimental and kinetic modeling study of a premixed nitromethane flame at low pressure, Proc.Comb. Inst., 32 (2009) 311-318.

[18] J. D. Nauclér, E. J. K. Nilsson, A. A. Konnov, Laminar burning velocity of nitromethane+air flames: A comparison of flat and spherical flames, Comb. Flame 162 (2015) 3803-3809.

[19] M. Faghih, Z. Chen, Two-stage heat release in nitromethane/air flame and its Impact on laminar flame speed measurement, Comb. Flame 183 (2017) 157-165.

[20] C. Brackmann, J. D. Nauclér, S. El-Busaidy, A. Hosseinnia, P.-E. Bengtsson, A. A. Konnov, E. J. K. Nilsson, Experimental studies of nitromethane flames and evaluation of kinetic mechanisms, Comb. Flame 190 (2018) 327-336.

[21] Z. Jia, Z. Wang, Z. Cheng, W. Zhou, Experimental and modeling study on pyrolysis of n-decane initiated by nitromethane, Comb. Flame 165 (2016) 246-258.

[22] J.-J. Weng, Z.-Y. Tian, K.-W. Zhang, L.-L. Ye, Y.-X. Liu, L.-N. Wu, D. Yu, J.-Z. Yang, C.-C. Cao, J.-B. Zou, Experimental and kinetic investigation of pyrolysis and oxidation of nitromethane, Comb. Flame 203 (2019) 247-254.

[23] J.C. Tricot, A. Perche, M. Lucquin, Gas phase oxidation of nitromethane, Comb. Flame 40 (1981) 269-291.

[24] Y.-X. Zhang, S. H. Bauer, Modeling the Decomposition of Nitromethane, Induced by Shock Heating, J. Phys. Chem. B 101 (1997) 8717-8726.

[25] K. Zhang, Y. Li, T. Yuan, J. Cai, P. Glarborg, F. Qi, An experimental and kinetic modeling study of premixed nitromethane flames at low pressure, Proc. Comb. Inst. 33 (2011) 407-414.

[26] P. A. Vlasov, N. M. Kuznetsov, Yu. P. Petrov, S. V. Turetskii, Nitromethane Isomerization during Its Thermal Decay, Kinetics and Catalysis 59 (2018) 6-10.

[27] P. Glarborg, J. A. Miller, B. Ruscic, S. J. Klippenstein, Modeling nitrogen chemistry in combustion, Prog. Energy Comb. Sci. 67 (2018) 31-68.

[28] P. Glarborg, A. B. Bendtsen, J. A. Miller, Nitromethane dissociation: implications for the $\mathrm{CH}_{3}+\mathrm{NO}_{2}$ reaction. Int. J. Chem. Kinet. 31 (1999) 591-602.

[29] O. Mathieu, C.R. Mulvihill, E.L. Petersen, Assessment of modern detailed kinetics mechanisms to predict CO formation from methane combustion using shock-tube laser-absorption measurements, Fuel 236 (2019) 1164-1180.

[30] C. R. Mulvihill, C. L. Keesee, T. Sikes, R. S. Teixeira, O. Mathieu, E. L. Petersen, Ignition delay times, laminar flame speeds, and species time-histories in the $\mathrm{H}_{2} \mathrm{~S} / \mathrm{CH}_{4}$ system at atmospheric pressure, Proc. Combust. Inst. 37 (2019) 735 742.

[31] J. Urzay, N. Kseib, D.F. Davidson, G. Iaccarino, R.K. Hanson, Uncertainty-quantification analysis of the effects of residual impurities on hydrogen-oxygen ignition in shock tubes, Comb.Flame, 161 (2014) 1-15.

[32] L. S. Rothman, D. Jacquemart, A. Barbe, D. Chris Benner, M. Birk, L. R. Brown, M. R. Carleer, C. Chackerian Jr., K. Chance, L. H. Coudert, V. Dana, V. M. Devi, J.-M. Flaud, R. R. Gamache, A. Goldman, J.-M. Hartmann, K. W. Jucks, A. G. Maki, J.-Y. Mandin, S. T. Massie, J. Orphal, A. Perrin, C. P. Rinsland, M. A. H. Smith, J. Tennyson, R. N. Tolchenov, R. A. Toth, J. Vander Auwera, P. Varanasi, G. Wagner, The HITRAN 2004 molecular spectroscopic database, J. Quant. Spectrosc. Radiat. Transf. 96 (2) (2005) 139-204.

[33] O. Mathieu, C. Mulvihill, E. L. Petersen, Shock-tube water time-histories and ignition delay time measurements for $\mathrm{H}_{2} \mathrm{~S}$ near atmospheric pressure, Proc. Combust. Inst. 36 (2017) 4019-4027.

[34] H. Nakamura, S. Hasegawa, Combustion and ignition characteristics of ammonia/air mixtures in a micro flow reactor with a controlled temperature profile, Proc. Combust. Inst. 36 (2017) 4217-4226.

[35] T. Kamada, H. Nakamura, T. Tezuka, S. Hasegawa, K. Maruta, Study on combustion and ignition characteristics of natural gas components in a micro flow reactor with a controlled temperature profile, Combust. Flame 161 (2014) 37-48. [36] Y. Kizaki, H. Nakamura, T. Tezuka, S. Hasegawa, K. Maruta, Effect of radical quenching on $\mathrm{CH}_{4} /$ air flames in a micro flow reactor with a controlled temperature profile, Proc. Combust. Inst. 35 (2015) 3389-3396.

[37] C. L. Rasmussen, A. E. Rasmussen, P. Glarborg, Sensitizing effects of NOx on CH4 oxidation at high pressure, Comb. Flame 154 (2008) 529-545. 
[38] Y. M. Choi, M. C. Lin, Kinetics and Mechanisms for Reactions of $\mathrm{HNO}$ with $\mathrm{CH}_{3}$ and $\mathrm{C}_{6} \mathrm{H}_{5}$ Studied by QuantumChemical and Statistical-Theory Calculations. Int. J. Chem. Kinet. 37 (2005) 261-274. 